\title{
How Emotional Intelligence and Language Learning Strategies Interact in an EFL Setting
}

\author{
Alireza Shakarami (Corresponding author) \\ Department of English, Kazerun Branch, Islamic Azad University, Kazerun, Iran \\ PO.Box: 7313913477 \\ E-mail: Shahkarami_alireza@yahoo.com \\ Hassan Khajehei \\ Department of English, Kazerun Branch, Islamic Azad University, Kazerun, Iran
}

Received: 12-09-2014

doi:10.7575/aiac.ijalel.v.4n.2p.229
Accepted: 15-11-2014

Published: 01-03-2015

URL: http://dx.doi.org/10.7575/aiac.ijalel.v.4n.2p.229

\begin{abstract}
Looking at learning procedure in general and language learning in particular, variations abound in learning processes and styles. Along this journey, some learners travel/move ahead smoothly and some others are faced with challenges of different sorts. Among the significant factors contributing to more effective and efficient language learning output, motivation, attitude, and personality traits play major roles. However, the role played by the intelligence seems to be critical in any language learning tasks and activities. Emotional Intelligence, which is believed to harmonize cognitive and emotional dispositions, seems to be indispensable to the interrelation between the learner's Multiple Intelligence makeup and respective preferred learning strategies. This can be used to develop materials and teaching tasks to become more or less compatible with the learners' varying preferences and abilities, thereby promoting their achievements. The findings of the study pertaining to the interrelation of students' Multiple Intelligence profile and their preferred Language Learning Strategies can be used to plan and categorize language learning and teaching tasks and materials in order to modify them more in accordance with the choice of the students. The educators might use the findings to choose from among various teaching materials to satisfy the needs of their learners with different illiteracies through conducting need analysis prior to choosing any learning and teaching content materials.
\end{abstract}

Keywords: Emotional Intelligence, Language Learning Strategies, Interrelation, EFL

\section{Background}

Whether cognition takes precedence over emotion or the reverse has been a matter of debate among philosophers for long. It is not known today who the forerunner(s) of the debate was, but according to available philosophical data, including Aristotle's school, intellect rather than emotion can serve as a reliable foundation for rational thought (Bar-On \& Parker, 2000). The same debate was also evident in early psychology. In a similar vein, early psychologists contended that intelligence is an entity devoid of emotion. The long standing trend, manifested in scientific discussions, was that higher order mental ability, i.e., intelligence is the cornerstone of abstract reasoning (Sternberg, 1997).

\subsection{Intelligence}

Abstract thinking is believed to be positively correlated with intelligence, the most influential factor in academic achievement. Terman (1921; cited in Sternberg, 1997, p. 339), as a pioneer of IQ tests, states that "an individual is intelligent in proportion as he is able to carry on abstract thinking".

According to (Brown, 1994), intelligence and second language learning are interrelated and memory is the key to language learning success. He opines "the greatest barrier to second language learning seemed to boil down to a matter of Memory"(p. 93). That is, learners with greater memory spans were believed to be more efficient ones because intelligence, then, was defined in terms of linguistic and logical-mathematical abilities.

The rise of new trend in the studies addressing intelligence was in early 1990s. Intelligence accordingly was no longer conceived of as linear and traditional mono-phasic intelligence and was revolutionized, Gardner (1983).

In his early Multiple Intelligence theory (MI), Gardner considered seven intelligences including intrapersonal and interpersonal intelligences which gave rise to other intelligences like emotional intelligence known as EI or EQ. Parallel with the new approach, interaction between emotion and thought was increasingly emphasized, leading to the concept of emotional intelligence in psychology in 1990s (Salovey \& Grewal, 2005).

\subsection{Emotional Intelligence}

By implication, $\mathrm{EQ} / \mathrm{EI}$ is responsible for rational use of emotion and existing corresponding information to make decisions (Ciarrochi \& Mayer, 2007). In other words, EI helps integrate our cognitive judgment and emotion in decision making process. The relationship between EI and academic success has been of great concern to recent 
studies (Elias, Arnold, \& Hussey, 2003); though, limited research have touched on the issue in ESL/EFL settings (Brackett \& Katulak, 2007). However, as (Brackett \& Katulak, 2007) state, few research attempted to study the concept in contexts where English is taught as a second or foreign Language (ESL/EFL), to get a comprehensive idea about its role on the Language Learning Strategy (LLS) choice that learners of English as foreign language employ to help them learn the new language more easily and effortlessly.

The present study seeks to determine the probable relationship between emotional intelligence and the choice of language learning strategies among Kazerun Islamic Azad university English language students. The sample population included 87 students majoring in English as a foreign language. The study used statistical procedure of mean analysis, correlation, and multiple regressions in order to identify the possible relationship between emotional intelligence and language learning strategy use. The instruments for collecting data were Bar-On Emotional Intelligence Questionnaire and Strategy inventory for Language Learning (SILL).

\section{The literature on Emotional Intelligence Research}

As demonstrated in Mayer, et al. (2000) research study, higher EQ can facilitate handling of emotional problems more efficiently and EQ serves as a marker for task performance. These groups, accordingly can behave more successfully in the conditions demanding more interactions and sociability, than those with lower EQ, and obtain higher scores in verbal and social intelligence. In addition, higher EQ inhibits negative behavioral features such as aggression and negative thought (Nelson \& Low, 2003, p. 43).

IQ has been considered for long as the key to success in any profession, however, studies including Boyatzis's (1982) revealed that other factors like self -awareness, as shown in successful managers, is also critical and help recognize one's strengths and weaknesses and consequently improve their deficiencies. Likewise, self-management can promote job efficiency, as demonstrated in the studies on psychologists, counselors, flight attendants, and small business owners. Emotional self-control and stress management are other benefits attributed to higher EQ. For example, business managers with higher EQ can better cope and deal with displeased customers while their overall performance remains unaffected by distracting factors (Lusch \& Serpkenci, 1990).

As shown in Spencer \&Spencer (1993), prominent leaders are capable of motivating others as an advantage and encourage them to pursue a collective goal in their performance. By definition, successful managers are those who understand others' emotions and possess positive skills such as self-awareness, self-management, social awareness, and relationship management which are crucial in greater occupational achievements and all stem from higher EQ (Goleman, 1998; Mayer, DiPaolo, \& Salovey, 1990), Goleman(1995). These findings lend support to the fact that EQ plays a more critical role than cognitive intelligence in job performance and dealing with the staff (Mayer, Salovey, \& Caruso, 2000). Furthermore, Goleman (1998) showed that EQ is more important than Cognitive intelligence. Mayer, et al. (2000) argue that emotional intelligence can foster outstanding job performance and as a basis for staff employment. They stated that group or team competences, like social awareness and social skills, enhance group EQ and therefor improve the culture, output, and effectiveness of the corporation. Group EQ is termed as "the ability of a group to generate a shared set of norms that manage the emotional process in a way that builds trust, group identity, and group efficacy"(Chemiss \& Goleman, 2001, p. 138).The major components of group EQ include Interpersonal competence and perspective holding, the former being the perception of the other's feelings and the latter being taking the others' viewpoints into consideration. Both aim to foster communication and elevate group performance in an organization.

The realization and implementation of the above concepts can be seen in brand and business organizations such as GE, Abbott Laboratories, Swatch, the Swiss watchmaker, and Canon, which put great emphasis on the study of EQ (Cooper \& Sawaf, 1997). Goleman(1998) contends that EQ plays a key role in hiring, staffing, and training of employees and keep the respective organization healthy and sound, and ultimately leading to their improved outputs. Unfortunately, a great number of employees are not equipped with such beneficial tools and as shown in a study (Boyatzis, 1999), $44 \%$ of workers lack group work skills and $80 \%$ a scarcity of work discipline, such as punctuality and hard-working. Employers needed employees outfitted with communication skills, sociability, and empathy, self-management, and teamwork tendencies: the skills very similar to the components of EQ.

The major question posed here is the possibility of EQ development in individuals. Research evidence gives a positive answer, as in a study in a MBA program, it was revealed that a 2 to 5 years program suffices for that purpose (Boyatzis, Goleman, \& Rhee, 2000). Once the program was fulfilled, students exhibited $86 \%$ improvement in their capabilities, which retained for three years upon graduation. The results also revealed that age and gender are positively correlated with EQ improvement (Bar-On, 1997; Dulewitz \& Higgs, 1999; Goleman, 1998).In a large study on 201 students at Henley Management College, a close association was found between age and the perception of sensitivity, i.e. older students obtained higher scores on EQ measure of sensitivity (Dulewitz \& Higgs, 1999). Also, results of some reported studies indicate that EQ, unlike IQ, consists of some competencies which develop with age, training, and experience (Goleman, 1998).

EQ studies pertaining to gender differences have come to a comprehensive conclusion that females typically score higher in empathy and social skills (Dulewitz \& Higgs, 1999; Schutte, et al., 1998). Although there seems not to be a big difference in overall performance of either of the two genders (Dawda \& Hart, 2000). But females seem to score higher in social skills and interpersonal strategies and empathy. The study supported a prior EQ study of university students which showed no gender bias in EI assessment (Dawda \& Hart, 2000).

\subsection{Learning strategies}

Learning strategy is defined as whatever actions and tricks taken by the learners to enhance their output, and make the task enjoyable and generalizable to novel situations (Oxford, 1990). As defined by Oxford, the three major types of 
direct language learning strategies (LLS) include, memory strategy which helps store the information in the long term memory and retrieve it whenever needed; cognitive strategy which is used for forming and revising the internal models and receiving and producing information in L2 and finally, compensation strategy which serves the learners to fill the gap in the language knowledge. Similarly, indirect LLS consists of three major types including Metacognitive strategy which helps learners to plan, monitor and evaluate their own learning processes; affective strategy, responsible for controlling learners' feelings, motivations and attitudes; and finally, social strategy which facilitates interaction with teachers and peers, mostly in discourse situations (Oxford, 1990).

\section{Methods}

Integrating strategies related to second language learning with emotional intelligence theory yields a framework for examining student behavior in early adolescent development. Such a situation provides a rich source of information for the researcher, particularly when research techniques yield data in a way that provides a suitable way of accessing student perceptions of learning. This study provides an opportunity to create a tapestry that weaves together the ideas of learning strategies to second language learning with emotional intelligence.

Understanding one's language learning strategies can help the learner improve their achievement in class. Perceiving the way learning strategies and emotional intelligence correlate, on the other hand, can open new doors to the learning process and help educators devise new methods to enhance the outcome of the learning setting.

3.1 Research questions

1. The study struggles to identify whether the emotional intelligence impacts the choice of language learning strategy use among Iranian EFL learners.

2. Is there a need for the language teachers to recognize the importance of relationship between emotional intelligence and language learning strategy use as a means of promoting interactivity among their students?

Data on the emotional intelligence and language learning strategies was collected quantitatively using already established inventories like (Bar-On, 2006) Emotional Quotient Inventory (EQ-i) and Strategy Inventory for Language Learning (Oxford's SILL, 1990) respectively. More analysis was then made to identify groupings of the high EQ users and their degree of use of language learning strategies. Tabulated data was then used to discuss the reciprocal interrelation of the EQ levels and the choice of language learning strategy use among the respondents of the study to establish the triangulation of the research data and culminate the relationship(s) between the subsets of the two inventories.

\subsection{Setting}

The research was performed in the Kazerun Islamic Azad University with random sampling from among the English students of the mentioned university as learners of English in an EFL setting. Eighty four English majoring students (two sections of students enrolled in two different subjects were randomly selected for the study). The possible relationship between the dependent variable and independent variable was established using the correlation coefficient and multiple regressions. The findings then were tabulated, analyzed and commented on to identify their effects and roles in the research discussion and implications.

\section{Results and Discussion}

Results and the findings of the quantitative part of the study are presented here in the form of four tables. They are analyzed and discussed from a qualitative point of view in the subsequent parts that may be revealing some facts about the choice of language learning strategy based on the perceived emotional intelligence.

Table 1. Descriptive Statistics of the Bar-On EQ Profiles of the Individuals $(N=84)$

\begin{tabular}{lllll}
\hline & Minimum & Maximum & Mean & S.D. \\
\hline IR & 22.00 & 35.00 & 27.5909 & 3.35717 \\
RE & 21.00 & 33.00 & 26.8409 & 2.76980 \\
EM & 19.00 & 35.00 & 26.5455 & 3.23825 \\
SR & 18.00 & 29.00 & 23.6591 & 2.30210 \\
HA & 17.00 & 26.00 & 21.5455 & 2.24597 \\
RT & 14.00 & 29.00 & 21.4091 & 3.35717 \\
OP & 14.00 & 25.00 & 21.2727 & 2.20321 \\
PS & 14.00 & 26.00 & 19.7727 & 2.47653 \\
AS & 15.00 & 23.00 & 18.0227 & 1.99405 \\
IC & 8.00 & 25.00 & 16.5455 & 4.03159 \\
ES & 12.00 & 20.00 & 15.8636 & 2.35847 \\
FL & 11.00 & 21.00 & 14.9773 & 2.28736 \\
ST & 10.00 & 18.00 & 14.5682 & 1.71719 \\
IN & 6.00 & 21.00 & 12.5455 & 3.06863 \\
SA & 2.00 & 9.00 & 5.1591 & 1.61307 \\
\hline
\end{tabular}


IJALEL 4(2):229-237, 2015

\begin{tabular}{|c|c|c|c|c|c|c|c|c|c|c|c|c|c|c|c|c|}
\hline & & $\begin{array}{l}\text { SR } \\
\end{array}$ & $\begin{array}{l}\mathbf{R E} \\
\end{array}$ & IC & PS & ES & $\mathbf{A S}$ & IN & FL & $\begin{array}{l}\text { ST } \\
\end{array}$ & IR & EM & $\begin{array}{l}\text { RT } \\
\end{array}$ & OP & HA & $\begin{array}{l}\text { SA } \\
\end{array}$ \\
\hline \multirow[t]{2}{*}{ SR } & $r$ & 1 & -.016 & -.142 & $.317^{\circ}$ & $.321^{*}$ & -.049 & .142 & -.002 & .256 & .087 & -.096 & -.033 & .289 & .181 & -.023 \\
\hline & $P$ & & .918 & .357 & .036 & .034 & .752 & .357 & .992 & .093 & .575 & .535 & .833 & . 057. & .240 & .884 \\
\hline \multirow[t]{2}{*}{ RE } & $r$ & -.016 & 1 & -.194 & .076 & -.132 & -.041 & -.124 & -.019 & .063 & $.330^{*}$ & $.757^{* *}$ & .102 & $.369^{*}$ & . 104 & -.161 \\
\hline & $P$ & .918 & & . 207 & .624 & .395 & .789 & .424 & 903 & .682 & .028 & .000 & .509 & .014 & .502 & .297 \\
\hline \multirow[t]{2}{*}{ IC } & $r$ & -.142 & -.194 & 1 & -.078 & .023 & .256 & $.586^{* *}$ & .059 & .075 & -.236 & -.193 & -.013 & -.135 & .226 & $.348^{*}$ \\
\hline & $P$ & .357 & . 207 & & .614 & .884 & .094 & .000 & .702 & .628 & .123 & .210 & .931 & .382 & .141 & .021 \\
\hline \multirow[t]{2}{*}{ PS } & $r$ & $.317^{*}$ & .076 & -.078 & 1 & -.001 & .119 & .258 & .036 & .184 & .033 & .158 & .084 & . 280 & .278 & .062 \\
\hline & $P$ & .036 & .624 & .614 & & .993 & .442 & .090 & .816 & .231 & .830 & .306 & .587 & .066 & .068 & 691 \\
\hline \multirow[t]{2}{*}{ ES } & $r$ & $.321^{*}$ & -.132 & .023 & -.001 & 1 & $.406^{* *}$ & .213 & $.344^{*}$ & .249 & $-.319^{*}$ & $-.392^{* *}$ & .207 & -.051 & -.008 & $.299^{*}$ \\
\hline & $P$ & .034 & .395 & .884 & .993 & & .006 & .165 & .022 & .103 & .035 & .009. & . 178 & . 743 & .961 & .048 \\
\hline \multirow[t]{2}{*}{ AS } & $r$ & -.049 & -.041 & . 256 & .119 & $.406^{* *}$ & 1 & $.405^{* *}$ & $.408^{* *}$ & .227 & -.207 & .002 & .221 & -.197 & . 288 & $.744^{* *}$ \\
\hline & $P$ & .752 & .789 & .094 & .442 & .006 & & .006 & .006 & . 138 & . 178 & .992 & . 150 & 199 & .058 & .000 \\
\hline \multirow[t]{2}{*}{ IN } & $r$ & . 142 & -.124 & $.586^{* *}$ & . 258 & .213 & $.405^{* *}$ & 1 & .234 & $.381^{*}$ & -.070 & -.192 & -.117 & .036. & . 256 & $.330^{*}$ \\
\hline & $P$ & .357 & .424 & .000 & . 090. & . 165 & .006 & & . 127. & .011 & .650 & .212 & .450 & .817 & .093. & .029 \\
\hline \multirow[t]{2}{*}{ FL } & $r$ & -.002 & -.019 & .059 & .036 & $.344^{*}$ & $.408^{* *}$ & .234 & 1 & . 288 & -.141 & -.064 & $.377^{*}$ & -.026 & -.007 & .070 \\
\hline & $P$ & .992 & .903 & .702 & .816 & . 022 & .006 & .127 & & .058 & .363 & .679 & .012 & .865 & 966 & .650 \\
\hline \multirow[t]{2}{*}{ ST } & $r$ & .256 & .063 & .075 & . 184 & .249. & .227 & $.381^{*}$ & . 288 & 1 & $.308^{*}$ & -.086 & -.182 & $.431^{* *}$ & $.334^{*}$ & .042 \\
\hline & $P$ & .093 & .682 & .628 & .231 & . 103 & . 138 & .011 & .058 & & .042 & .577 & .236 & . 003 & .027 & .786 \\
\hline \multirow[t]{2}{*}{ IR } & $r$ & .087 & $.330^{*}$ & -.236 & .033 & $-.319^{*}$ & -.207 & -.070 & -.141 & $.308^{*}$ & 1 & $.361^{*}$ & -.175 & $.390^{* *}$ & $.598^{* *}$ & -.275 \\
\hline & $P$ & .575 & . 028. & .123 & .830 & .035 & .178 & .650 & .363 & .042 & & . 016 & .257 & .009 & .000 & .070 \\
\hline \multirow[t]{2}{*}{ EM } & $r$ & -.096 & $.757^{* *}$ & -.193 & .158 & $-.392^{* *}$ & .002 & -.192 & -.064 & -.086 & $.361^{*}$ & 1 & .129 & . 184 & .153 & -.159 \\
\hline & $P$ & .535 & . & . 210 & .306 & .009. & 992 & .212 & .679. & .577 & .016. & & .405 & .232 & .321 & .301 \\
\hline \multirow[t]{2}{*}{ RT } & $r$ & -.033 & .102 & -.013 & .084 & 207 & .221 & -.117 & $.377^{*}$ & -.182 & -.175 & . 129 & 1 & -.138 & .176 & .134 \\
\hline & $P$ & .833 & .509 & .931 & .587 & . 178 & . 150 & .450 & .012 & .236 & .257 & .405 & & .371 & .252 & .387 \\
\hline \multirow[t]{2}{*}{ OP } & $r$ & .289 & $.369^{*}$ & -.135 & .280 & -.051 & -.197 & .036 & -.026 & $.431^{* *}$ & $.390^{* *}$ & .184 & -.138 & 1 & .265 & $-.392^{* *}$ \\
\hline & $P$ & .057. & .014 & .382 & .066 & .743 & 199 & .817 & .865 & .003 & .009. & .232 & .371 & & .082 & .008 \\
\hline \multirow[t]{2}{*}{ HA } & $r$ & .181 & . 104 & .226 & .278 & -.008 & .288 & .256 & -.007 & $.334^{*}$ & $.598^{* *}$ & .153 & .176 & .265 & 1 & 187 \\
\hline & $P$ & .240 & .502 & .141 & .068 & .961 & .058 & .093 & .966 & .027 & .000 & .321 & .252 & .082 & & .223 \\
\hline \multirow[t]{2}{*}{ SA } & $r$ & -.023 & -.161 & $.348^{*}$ & .062 & $.299^{*}$ & $.744^{* *}$ & $.330^{*}$ & .070 & .042 & -.275 & -.159 & .134 & $-.392^{* *}$ & . 187 & 1 \\
\hline & $P$ & .884 & 297 & .021 & .691 & .048 & .000 & .029 & .650 & . 786 & . 070. & .301 & .387 & .008 & .223 & \\
\hline
\end{tabular}

*. Correlation is significant at the 0.05 level (2-tailed).

**. Correlation is significant at the 0.01 level (2-tailed).

Table 3. Pearson Product-Moment Correlation between Bar-on EQ Categories and SILL $(N=84)$

\begin{tabular}{|c|c|c|c|c|c|c|c|}
\hline & & Memory & Cognitive & Compensation & Metacognitive & Affective & Social \\
\hline \multirow[t]{2}{*}{ SR } & $R$ & -.176 & -.221 & -.085 & -.006 & .005 & -.083 \\
\hline & $P$ & .252 & .150 & .584 & .969 & .972 & .592 \\
\hline \multirow[t]{2}{*}{ RE } & $R$ & .046 & -.120 & -.163 & .007 & .131 & .002 \\
\hline & $P$ & .765 & .439 & .291 & .966 & .397 & .988 \\
\hline \multirow[t]{2}{*}{ IC } & $R$ & .157 & .162 & .290 & .212 & .121 & .150 \\
\hline & $P$ & .310 & .293 & .056 & .168 & .433 & .332 \\
\hline \multirow[t]{2}{*}{ PS } & $R$ & -.022 & .103 & -.052 & .025 & -.032 & .063 \\
\hline & $P$ & .887 & .508 & .739 & .872 & .839 & .685 \\
\hline \multirow[t]{2}{*}{ ES } & $R$ & -.062 & $-.394^{* *}$ & .013 & $-.299^{*}$ & -.189 & -.182 \\
\hline & $P$ & .688 & .008 & .933 & .048 & .218 & .237 \\
\hline \multirow[t]{2}{*}{ AS } & $R$ & .066 & -.248 & .196 & -.259 & .080 & -.252 \\
\hline & $P$ & .673 & .105 & .203 & .090 & .608 & .099 \\
\hline \multirow[t]{2}{*}{ IN } & $R$ & .297 & .062 & .240 & .186 & .269 & .049 \\
\hline & $P$ & .050 & .689 & .117 & .226 & .077 & .750 \\
\hline \multirow[t]{2}{*}{ FL } & $R$ & .012 & .075 & $.376^{*}$ & -.165 & -.069 & -.063 \\
\hline & $P$ & .936 & .627 & .012 & .285 & .655 & .686 \\
\hline \multirow[t]{2}{*}{ ST } & $R$ & .211 & -.021 & .274 & .173 & .226 & .011 \\
\hline & $P$ & .170 & .892 & .072 & .263 & .140 & .943 \\
\hline \multirow[t]{2}{*}{ IR } & $R$ & .238 & .077 & .152 & $.366^{*}$ & .290 & .071 \\
\hline & $P$ & .119 & .619 & .324 & .014 & .056 & .646 \\
\hline \multirow[t]{2}{*}{ EM } & $R$ & .144 & .195 & -.012 & .154 & .262 & .094 \\
\hline & $P$ & .350 & .205 & .938 & .317 & .086 & .542 \\
\hline \multirow[t]{2}{*}{ RT } & $R$ & $-.374^{*}$ & -.016 & $.320^{*}$ & -.136 & -.265 & .106 \\
\hline & $P$ & .012 & .917 & .034 & .380 & .082 & .493 \\
\hline \multirow[t]{2}{*}{ OP } & $R$ & .196 & -.033 & -.076 & $.332^{*}$ & .119 & .119 \\
\hline & $P$ & .203 & .832 & .626 & .028 & .442 & .440 \\
\hline \multirow[t]{2}{*}{ HA } & $R$ & .103 & .028 & .293 & .297 & .218 & .016 \\
\hline & $P$ & .506 & .855 & .053 & .050 & .156 & .919 \\
\hline \multirow[t]{2}{*}{ SA } & $R$ & -.107 & -.219 & .154 & -.211 & .145 & -.113 \\
\hline & $P$ & .489 & .153 & .319 & .170 & .348 & .464 \\
\hline
\end{tabular}

*. Correlation is significant at the 0.05 level (2-tailed).

**. Correlation is significant at the 0.01 level (2-tailed). 


\begin{tabular}{ll}
\hline Bar-on EQ & SILL \\
\hline $\mathbf{. 1 4 5}$ & .223 low correlation \\
\hline $\boldsymbol{N}=84$, Sig.(2-tailed)
\end{tabular}

A quick look at the quantitative data of the study showcase that there is no significant correlation between the two variables of the research; however, careful scrutiny and deeper analysis based on the qualitative data reveals some delicate and fundamental relationship between the students' MI profile and their choice of learning strategy use.

Respondents reported in their retrospective self-reported questionnaires that they are mostly of IR (interpersonal) subset type among the scales of the Bar-On inventory for emotional intelligence. The mean score for their EQ use was $\mathrm{M}=27.5909$ with a standard deviation of $\mathrm{SD}=3.35717$. The Pearson product moment shows that IR group of respondents are highly associated with those with higher RE (Social responsibilities), ES (emotional self-awareness), ST (stress tolerance), EM (empathy), OP (optimism), and HA (happiness). A second Pearson product moment correlation shows that IR respondents use Metacognitive strategies as their highest preferred language learning strategy and Social strategies as the lowest used one.

To put it in other words, we can argue that students with higher interpersonal intelligence who have higher ability to form and maintain emotional based relationships have higher capabilities to be aware of their emotions, can manage their emotions effectively, understand the others' emotions, needs, and feelings. They are able to be positive, hopeful and look at the brighter side of life and have the ability to feel content with oneself, others and their life. Their high use of Metacognitive language learning strategies may suggest their ability to exercise 'executive control' through planning, arranging, focusing, and evaluating their own learning. We can propose that their choice of Metacognitive strategies as the highly preferred strategy, comes from their RE, ES, ST, EM, OP, and HA intelligences because all these subsets of emotional intelligence, in one way or another, suggest capability to "use their mind and feelings to control, evaluate, arrange, plan, and focus on their language learning task"(Oxford, 1990, p. 71). The low level of Social strategies use can also support the justification through high independence feeling and less dependence on the others as learning aids.

The second highest EQ users among our respondents were RE (Social responsibility) users with a mean score of M= 26.8409 and $\mathrm{SD}=2.76980$. The Pearson product moment correlation shows that they have significant correlation with those with higher IR (interpersonal relationships), EM (empathy), and OP (optimism). Although Pearson product correlation did not show any significant correlation for RE respondents with any of the language learning strategies, but it does not mean that this group of learners do not use any strategy in their language learning. Data from table 3 tells us that these group deal most with the Compensation strategies.

Based on the explanation, the RE group of learners have the ability to identify with his/her Social group and cooperate with others at various tasks. This subset of their emotional intelligence goes hand in hand with their ability to form and maintain intimate emotional relationships with others, understand others' emotions, feelings, and needs and their ability to be positive and hopeful. As mentioned earlier in the text, there is no significant correlation between the RE group and language learning strategies; however, they moderately use Compensation strategies to "overcome any gaps in knowledge of the language" (Oxford, 1990, p. 71). IR, EM, and OP subsets of their emotional intelligence may indicate that they consult knowledge sources, are open, and accept the missing knowledge willingly.

The third group of higher EQ users was EM (empathy) group with a mean of $\mathrm{M}=26.5455$, and a standard deviation $\mathrm{SD}=3.23825$. Based on the data from table 2, the correlation coefficient between the EM respondents and those with higher RE (Social responsibilities), ES (emotional self-awareness), and IR (interpersonal relationships) are highly significant. Table 3 on the other hand, shows that the EM group's emotional intelligence has no significant correlation with the language learning strategies. But a closer look reveals the fact that they use the Affective strategies as their highest strategies.

The literature tells us that EM group members have the ability to be aware of and understand the others' emotions, feelings, and needs. This is in line with their ability to identify with their Social group and cooperate with others. They tend to be aware of their emotions and are capable of forming and maintaining emotional relationships. The language learning strategies which are preferred by the EM group are to some extent indicative of their emotional intelligence in that Affective strategies "enable learners to control feelings, motivations, and attitudes related to language learning" (Oxford, 1990, p. 71). Emotions, attitudes, and affect management seems to be the strong point of our proposition here.

The fourth rank for EQ use goes for the SR (self-regard) respondents with a mean of M= 23.6591 and standard deviation of $\mathrm{SD}=2.30210$. The correlation coefficient is proved to be significant between SR group and PS (problem solving) and ES (emotional self-awareness) groups. As for their preferred language learning strategies, Cognitive strategies seem to be the highest set of strategies used by this group of respondents.

SR group learners have the ability to view, assess, and accept themselves as well as their emotions. They are highly associated with the ES group that are aware of and understand their own feelings and emotions. They are also associated with those who have the determination and capability to solve the problem they encounter in every aspect of life. As for the common preferred type of language learning strategy they would rather Cognitive strategies "for forming and revising internal mental models and receiving and producing messages in the target language" (Oxford, 1990, p. 71). The strong point of our proposition in relating SR, PS, and ES groups with Cognitive strategies use seems 
to be the inclination to count on their own abilities to view, assess, and have the determination and ability to solve their problems.

HA (happiness) seem to have the fifth rank among the high EQ user respondents. The mean for HA group is M= 21.5455 and the standard deviation is $\mathrm{SD}=2.24597$. Data from table 2 tell us that this sub scale of Emotional Intelligence is highly correlated with ST (stress tolerance) and IR (interpersonal relationship). Table 3 on the other hand, supplies us with the language learning strategy type they use. Metacognitive strategies are reported as the highly used strategies.

Based on the clarifications made by (Bar-On, 2006), HA group have the ability to feel content with themselves and others and life in general. The correlation with ST and IR groups tell us that they have the ability to manage their emotions, and form and maintain emotional relationship with others. Their preferred language learning strategies are reported to be Metacognitive strategies which "help learners exercise 'executive control' through planning, arranging, focusing, and evaluating their own learning"(Oxford, 1990, p. 71). It seems that the HA groups' ability to control, manage, and arrange their emotions indicates a kind of tendency which takes its root from inner emotional intelligence of the informants.

Reality testing (RT) group is proved to have the sixth rank of high EQ users. The mean for reality testing group is M= 21.4091, and standard deviation $\mathrm{SD}=3.35717$. RT group seem to have a significant correlation with FL (flexibility) group. Data from table 3 tell us that there are strong positive correlation between the RT group of respondents and the high use of Memory and Compensation strategies.

(Bar-On, 2006)defines the Reality testing (RT) group as those who have the ability to validate their own thinking and feelings. The RT group shows a strong correlation with FL group who have the ability to manage change and adapt to new situations. Their preferred language learning strategies are reported to be Memory as "aid in entering information into long-term Memory and retrieving information when needed for communication"(Oxford, 1990, p. 71) and Compensation strategies as "strategies to overcome any gaps in knowledge of the language" (Oxford, 1990, p. 71). Our proposed interrelationship between the subsets of emotional intelligence and language learning strategies seems to take its root from the respondents' ability to manage the Cognitive change formed by language learning, adapt to new learning situation, and trying to overcome the linguistic knowledge gap when encountered.

The seventh rank of the high EQ users' list goes for the Optimism (OP) group with a mean of M=21.2727 and standard deviation of $\mathrm{SD}=2.20321$. Strong positive correlations are reported between the OP group with the RE (Social responsibility), ST (stress tolerance), IR (interpersonal relationship), and SA (self-actualization). Table 3, on the other hand tells us that OP group of respondents have a strong tendency to use Metacognitive strategies as the highest preferred strategies.

Optimism (OP) is defined by (Bar-On, 2006)as the ability to be positive and hopeful. OP group shows strong positive correlations with RE as the ability to identify with the group members and cooperate with others, and ST as the ability to manage ones' emotion, and IR as the ability to form and maintain emotional relationships with others, and SA as the ability to set personal goals and inner drive to achieve them. The preferred strategy type for OP group was shown to be Metacognitive strategies which "help learners exercise 'executive control' through planning, arranging, focusing, and evaluating their own learning" (Oxford, 1990, p. 71). The interdependence proposition enables us to justify that it is the respondents' inner ability to control their emotion, set their learning goals, and drive to achieve them through executive control i.e. planning, focusing and evaluating their language learning.

Table 1 reveals that the eight rank of the EQ users' list goes for the PS (problem solving) group of respondents. The mean of EQ use for PS group is $\mathrm{M}=19.7727$ and standard deviation $\mathrm{SD}=2.47653$ based on the data from table 1 per se. Data from table 2 tell us that this sub scale of Emotional Intelligence has strong correlation with SR (self-regard). On the other hand, table 3 reveals that this group of respondents has no strong correlation with any type of language learning strategy use; although, they tend to use more Cognitive strategies.

The literature explains PS (problem solving) group as the ability to identify, evaluate, and try to resolve the encountered problems through thinking about and focusing on the problem. PS group shows a strong positive correlation with SR (self-regard) which is the ability to view, assess, and accept oneself including one's emotion. The preferred strategy for the PS group is reported to be Cognitive strategies which "are used for forming and revising internal mental models and receiving and producing messages in the target language"(Oxford, 1990, p. 71).Through our interrelationship proposition, we can justify that the problem solving group use their mental capabilities more to identify, evaluate, and focus on the language problem they encounter. They make mental linguistic models, focus on the problems, evaluate, revise, and try to resolve the linguistic problems.

The nine rank of the high EQ users' list goes for the AS (assertiveness) with a mean of M=18.0227 and standard deviation of $\mathrm{SD}=1.99405$. Table 2 tells us that this subgroup of high EQ users has strong correlations with ES (emotional self-awareness), IN (independence), FL (flexibility), and SA (self-actualization). There is no report of strong correlation with any type of language learning strategy use based on the data from table 3; however, they seem to be in favor of Metacognitive strategy in their moderate use of this strategy.

AS (assertiveness) is defined by (Bar-On, 2006) as the ability to express one's emotions and oneself nondestructively. AS has strong correlations with ES as the ability to be aware of and understand one's emotions, IN as the ability to be self-reliant and free of emotional dependency on others in the way one thinks and behaves, FL as the ability to make change and adapt to new situations, and SA as the ability to set personal goals and inner drive to achieve them. The 
preferred strategy for the AS group is reported to be Metacognitive strategies which "help learners exercise 'executive control' through planning, arranging, focusing, and evaluating their own learning"(Oxford, 1990, p. 71). Our proposed interrelationship could be explained through Metacognition which could be effectively linked to the inner drive for this group of informants to be self-reliant and free from dependency to others. They set mental linguistic goals, develop inner drive, focus on, and arrange to achieve their goals.

Table 1 reveals that the tenth rank of the high EQ users' list goes for the IC (impulse control) with a mean of M= 16.5455 and standard deviation of $\mathrm{SD}=4.03159$. Data from table 2 shows that this group of high $\mathrm{EQ}$ users has strong correlation with IN (independence) and SA (self-actualization). No strong correlation is reported between the IC group and any type of language learning strategy use; though, they tend to use Compensation strategies more.

IC (impulse control) is defined by (Bar-On, 2006) as the ability to effectively control one's emotions. IC is shown to have strong positive correlation with IN as the ability to be self-reliant and free of emotional dependency on others in the way one thinks and behaves, SA as the ability to set personal goals and inner drive to achieve them. The preferred strategy for the IC group is reported to be Compensation strategies which "are needed to overcome any gaps in knowledge of the language" (Oxford, 1990, p. 71). Through our interrelationship proposition, we can argue that the ability to control emotion, set personal goals and inner drive to achieve them could be well justified through the recognition of one's weaknesses and motivation to compensate for the missing linguistic knowledge by means of Compensation strategies.

ES (emotional self-awareness) is reported to have the eleventh rank of the high EQ users' list. The reported mean of the group is $\mathrm{M}=15.8636$ and standard deviation $\mathrm{SD}=2.35847$. The $\mathrm{ES}$ group has strong positive correlation with $\mathrm{SR}$ (selfregard), AS (assertiveness), FL (flexibility), EM (empathy), and SA (self-actualization). Table 3 shows that this group of high EQ users has a strong positive correlation with the Cognitive language learning strategy use at the first place and Metacognitive strategies at the second place.

Emotional self-awareness (ES) is explained by (Bar-On, 2006) as the ability to be aware of and understand one's emotions. ES has strong positive correlation with SR as the ability to view, assess, and accept oneself including one's emotion, AS that is the ability to express one's emotions and oneself nondestructively, FL as the ability to manage change and adapt to new situations, EM as the ability to be aware of and understand others' emotions, feelings, and needs, and SA as the ability to set personal goals and inner drive to achieve them. The preferred strategy type for the AS group is reported to be Cognitive strategies which are used for forming and revising internal mental models and receiving and producing messages in the target language" and Metacognitive strategies that "help learners exercise 'executive control' through planning, arranging, focusing, and evaluating their own learning"(Oxford, 1990, p. 71). Our proposed interrelationship could be explained through Cognitive and Metacognitive strategy use which could be effectively linked to the inner drive for this group of informants to form mental models, revise them, and be self-reliant and free from dependency to others. They set mental linguistic goals, develop inner drive, focus on, and arrange to achieve their goals.

The twelfth rank of the high EQ users' list goes for the FL (flexibility) with a mean of M=14.9773 and standard deviation of $\mathrm{SD}=2.28736$. The FL group has strong positive correlation with the ES (emotional self-awareness), AS (assertiveness), and RT (reality testing). Data from table 3 tell us that FL group of respondents has a strong positive correlation with Compensation language learning strategy use.

Flexibility(FL) is explained by (Bar-On, 2006) as the ability to manage change and adapt to new situations. FL group shows strong positive correlation with the ES as the ability to be aware of and understand one's emotions, AS that is the ability to express one's emotions and oneself nondestructively, RT as the ability to validate one's thinking and feelings. The preferred language learning strategies used by FL group are shown to be Compensation strategies that "are needed to overcome any gaps in knowledge of the language" (Oxford, 1990, p. 71). We propose our interrelationship here as the FL groups are aware of their feelings, express their emotions, and validate their mental process, review, monitor, revise, and reshape their mental processes which are possible through Compensation strategy use.

Based on the data presented in table 1 we understand that the thirteenth rank of the high EQ users' list goes for the ST (stress tolerance) with a mean value of $\mathrm{M}=14.5682$ and standard deviation of $\mathrm{SD}=1.71719$. The $\mathrm{ST}$ group shows strong positive correlations with IN (independence), IR (interpersonal relationships), OP (optimism), and HA (happiness). Table 2 on the other hand, tells us that this group shows no strong correlation with any of the language learning strategy use; however, they seem to use more Compensation strategies.

Stress tolerance (ST) is defined in the literature by (Bar-On, 2006) as the ability to effectively manage one's emotions. ST group shows strong positive correlations with IN as the ability to be self-reliant and free from emotional dependency on others in the way one thinks and behaves, IR as the ability to form and maintain intimate emotional relationship with others, OP as the ability to be positive and hopeful, and HA as the ability to feel content with one self, others, and life in general. The preferred language learning strategies for ST group are reports as Compensation strategies that are "are needed to overcome any gaps in knowledge of the language" (Oxford, 1990, p. 71). The proposition pertaining to the interrelationship of the two variables of this study i.e. emotional intelligence and choice of language learning strategies makes it possible to argue that the ST group easily manage their feelings, are self-reliant, positive, and feel content with life in general. Managing emotions, reviewing, revising, mental processes and being open in general are qualities needed for the Compensation strategy users. 
IN (independence) is reported to have the fourteenth rank of the high EQ users' list. The reported mean of the group is $\mathrm{M}=12.5455$ and standard deviation of $\mathrm{SD}=3.06863$. Table 2 shows that the $\mathrm{IN}$ group has strong positive correlations with IC (impulse control), AS (assertiveness), ST (stress tolerance), and SA (self-actualization) groups. Data from table 3 tells us that the IN group of respondents have no strong correlation with any of the language learning strategy use; however, they seem to use more Memory strategies.

Independence (IN) is defined by (Bar-On, 2006)as the ability to be self-reliant and free from emotional dependency on others in the way one thinks and behaves. IN group have strong positive correlations with IC as the ability to effectively control one's emotion, AS that is the ability to express one's emotions and oneself nondestructively, ST as the ability to effectively manage one's emotions, and SA as the ability to set personal goals and inner drive to achieve them. The preferred strategy type for the IN group is reported to be Memory strategies. Memory strategies are "aid in entering information into long-term Memory and retrieving information when needed for communication"(Oxford, 1990, p. 71). The interrelationship proposition here seems to emphasize on the independence of emotion, its expression, control, and management which facilitates free entering information into long term Memory without any inhibition.

The last rank of the high EQ users' list goes for the SA (self-actualization) with a mean score of $\mathrm{M}=5.1591$ and standard deviation of $\mathrm{SD}=1.61307$. Data on table 2 shows that the $\mathrm{SA}$ group has strong positive correlations with IC (impulse control), ES (emotional self-awareness), AS (assertiveness), IN (independence), and OP (optimism).Data from table 3 shows that the SA group represents no strong correlation with any of the language learning strategies; hence, they seem to use more Cognitive strategies.

Self-actualization(SA) is explained by (Bar-On, 2006)as the ability to set personal goals and inner drive to achieve them. SA group shows strong positive correlations with IC as the ability to effectively control one's emotion, ES as the ability to be aware of and understand one's emotions, AS that is the ability to express one's emotions and oneself nondestructively, IN as the ability to be self-reliant and free from emotional dependency on others in the way one thinks and behaves, and OP as the ability to be positive and hopeful. The preferred language learning strategies for SA group are reports as Cognitive strategies that "are used for forming and revising internal mental models and receiving and producing messages in the target language"(Oxford, 1990, p. 71). The proposition pertaining to the interrelationship of the two variables of this study suggests that SA group members positively set their mental linguistic goals, are aware of their emotions, are self-dependent, express their feelings freely, and revise their mental processes to achieve their goal of language learning.

\section{Implication}

The present study intended to investigate the probable relationship between Emotional Intelligence and Learning Strategies. The Quantitative and qualitative findings point to the importance of emotional side of the learners; as Lawson (2011, p.71) stipulates, "emotions are the relay stations between sensory input and thinking. When the input is interpreted positively, we are motivated to act and achieve a goal. When the input is interpreted negatively, we do not act and do not learn. Negative emotions (Anxiety, depression and anger or frustration) can interfere with learning and can result from problems with learning, creating a maladaptive and self-defeating pattern of behavior, which prevents learning and stunts mental/emotional growth". The quantitative part of the research indicates a low positive relationship between students' average emotional intelligence and learning strategies. However, the qualitative data reveal a profound and deep interrelation between the two variables of the study. The findings may shed some light on the field of EFL learning and teaching profession in Iran.

In planning instruction for a learner or groups of learners, a teacher may wish to target all the intelligences of a specific domain to provide for experiences that strengthen that particular domain. Based on the theory of Multiple Intelligences (MI), a person may be viewed as intelligent in any of these areas, and the identification of the dominant intelligence type has proven to have pedagogic implications. One way to produce competent, effective citizens is to help our students and to empower them to plan, monitor and reflect. Assist them to know more about their feelings and their learning, guide them to develop goals, and cooperate with others. According to "If students are to develop essential life skills and the ability to think constructively and act wisely, the emotional mind must be understood and considered central to education for the 21 st century" (2006, p. 1). EI skills synchronize the Cognitive and emotional mindsets and are essential to effective behavior.

Teachers and pedagogic officials may take the result of this research study in order to plan and categorize language learning and teaching tasks and materials in order to make them more in accordance with the choice of their students. The findings may also serve as recommendations for educators to modify instruction and offer various learning opportunities to the learners. They might help educators select a variety of appropriate teaching materials to meet the needs of learners with different abilities. Therefore, conducting a need analysis prior to choosing any teaching materials, based on the educators need seem to fit more to students' MI profile and to enable programmers to select the learning tasks and activities accordingly.

In fact, the findings of this study can help teachers improve their literacy instruction, as they require feedback on their job in order to adjust their instruction to better meet the needs of the students. Thus, one of the implications of the new understanding is that once a teacher has a picture of the students' strengths and weaknesses in different intelligence areas, s/he can help them realize and develop their intellectual capabilities accordingly. Therefore, the findings can provide teachers with further insights into factors involved in determining a MI profile of the Iranian EFL pre-university learners. 
Finally, kind of screening test seems possible to place students into different expectation groups based on their Emotional Intelligence and Learning Strategy tests in order to understand what to expect from which group of students. Teachers might be able to administer EI and LS tests after the entries prove to be cognitively competent for their chosen field of study. This study as a part of activities of educational planners is targeted in the enhancement of learning for the group of peer language learners and possibly individual ones.

\section{References}

Bar-On, R. E. (1997). BarOn Emotional Quotient Inventory: Technical manual. Toronto, Canada: Multi-Health Systems Inc.

Bar-On, R. E. (2006). The Bar-On model of emotional-social intelligence (ESI) 1. Psicothema, 18(Suplemento), $13-25$. Boyatzis, R. E. (1982). The Competent Manager: A Model for Effective Performance. New York, NY: John Wiley \& Sons.

Boyatzis, R. E. (1999). Self-directed change and learning as a necessary meta-competency for success and effectiveness in the 21 st century. In R. Sims \& J. G. Veres (Eds.), Keys to Employee Success in the Coming Decades (pp. 15-32). Westport, CT: Greenwood Publishing.

Boyatzis, R. E., Goleman, D., \& Rhee, K. (2000). Clustering competence in emotional intelligence: Insights from the Emotional Competence Inventory (ECI). Handbook of emotional intelligence, 343-362.

Chemiss, C., \& Goleman, D. (2001). The Emotionally Intelligent Workplace* Jossey-Bass. San Francisco, CA.

Cooper, R. K., \& Sawaf, A. (1997). Executive EQ: Emotional intelligence in leadership and organizations. New York: Grosset/Putnam.

Dawda, D., \& Hart, S. D. (2000). Assessing emotional intelligence: Reliability and validity of the Bar-On Emotional Quotient Inventory (EQ-i) in university students. Personality and Individual Differences, 28(4), 797-812.

Dulewitz, V., \& Higgs, M. (1999). “Can emotional intelligence be measured and developed?”. Leadership \& Organization Development Journal, 20(5), 242-252.

Goleman, D. (1995). Emotional intelligence: Why it can matter more than IQfor character, health and lifelong achievement. New York: Bantam Books.

Goleman, D. (1998). Working with emotional intelligence. New York: Bantam Books.

Lusch, R. F., \& Serpkenci, R. (1990). Personal differences, job tensions, job outcome and store performance: A study of retail managers Journal of Marketing.

Mayer, J. D., DiPaolo, M., \& Salovey, P. (1990). Perceiving affective content in ambiguous visual stimuli: A component of emotional intelligence. Journal of personality assessment, 54(3-4), 772-781.

Mayer, J. D., Salovey, P., \& Caruso, D. R. (2000). Models of emotional intelligence. In R. J. Sternberg (Ed.), Handbook of Intelligence (pp. 396-420). Cambridge, England: Cambridge University Press.

Nelson, D. B., \& Low, G. R. (2003). Emotional intelligence: Achieving academic and career excellence. MIND, 97, 145 .

Oxford, R. L. (1990). Language learning strategies: What every teacher should know. New Yourk: Newbury House Publishers.

Schutte, N. S., Malouff, J. M., Hall, L. E., Haggerty, D. J., Cooper, J. T., Golden, C. J., et al. (1998). Development and validation of a measure of emotional intelligence. Personality and individual differences, 25(2), 167-177. 